\title{
Right Posteromedial Apical Peripheral Zone of Prostate
}

National Cancer Institute

\section{Source}

National Cancer Institute. Right Posteromedial Apical Peripheral Zone of Prostate. NCI

Thesaurus. Code C128583.

The region of the prostate that is located on the anatomical right side of the posteromedial portion of the apical division of the peripheral zone. 